Xiaoping Zhan, Zhenmin Mao*, Jian Chen and Yuankui Zhang

\title{
Acrylate copolymer: a rate-controlling membrane in the transdermal drug delivery system
}

\begin{abstract}
A film-like copolymer composed of 2-hydroxy3-phenoxypropylacrylate, 4-hydroxybutyl acrylate and cyclohexyl methacrylate was synthesized and exploited as a rate-controlling membrane in the transdermal drug delivery systems (TDDs). A series of acrylate copolymers with different formulations were characterized by Fourier transform infrared spectroscopy, differential scanning calorimetry and tensile strength, and then evaluated by clonidine hydrochloride transporting through the films. It was found that the formulation M2 composed of three monomers at a ratio of 4:4:2(w/w/w) showed excellent mechanical and permeation properties. The optimal formulation M2 was further characterized by scanning electron microscopy, contact angles and swelling ratio, and then the permeation behaviors of five different physicochemical drugs transporting through the M2 were evaluated. The results showed that the permeation behaviors were influenced by many factors including the thickness of the membrane, the physicochemical properties of the drugs, the dose of the drugs and the interactions between the drugs and the membrane. This type of copolymer membrane might open new applications in the field of TDDs.
\end{abstract}

Keywords: drug delivery system; permeation; polyacrylate; rate-controlling membrane; transdermal.

DOI 10.1515/epoly-2014-0123

Received July 11, 2014; accepted December 3, 2014

\section{Introduction}

Compared with oral and injectable administration, transdermal drug delivery systems (TDDs) have many advantages including improved bioavailability, reduced dose frequency and adverse reaction, which result in a sustained and constant drug delivery rate and enhanced

*Corresponding author: Zhenmin Mao, School of Pharmacy, Shanghai Jiaotong University, Shanghai 200240, China, e-mail:zmmao@sjtu.edu.cn

Xiaoping Zhan, Jian Chen and Yuankui Zhang: School of Pharmacy, Shanghai Jiaotong University, Shanghai 200240, China patient compliance $(1,2)$. TDDs are usually divided into two different categories: one is the matrix type, in which the drug is dispersed in a matrix layer, and the other is the reservoir type, in which the drug is sandwiched between a backing layer and a rate-controlling layer $(3,4)$. In the reservoir type, the rate-controlling layer is a very important component because it ensures drug delivery at a sustained rate following expected requirements $(5,6)$.

Currently, several film-like polymers are used as the rate-controlling layer including 1 . hydrogel membrane (711), such as polyacrylic acid (12), chitosan (13-16), alginate (17) and polysaccharide (18); 2. nanofibrous membrane (19), such as polylactide-polyglycolide (PLGA) $(20,21)$ and polycaprolactone/polyvinylpyrrolidone (PCL/PVP) composites (22); 3. polyampholyte latex membrane (23), such as acrylic acid and co-2-(diethylamino)ethyl methacrylate $(24,25) ; 4$. and non-degradable polymer membrane, such as polyethylene $(6,26)$, ethylene vinyl acetate $(27,28)$, nylon $(29,30)$, polyacrylate $(31,32)$, rubber $(33,34)$ and silica mesostructures $(35,36)$. Among the non-degradable polymer membranes, permeation at a zero order is usually observed because drug molecules transport through the membrane via the pores fabricated by polymer chains instead of degradation or dissolution of polymer (31-34).

Polyacrylates are widely used as pressure-sensitive adhesives in TDDs because of their good compatibility with a very wide range of drugs and excipients, ease of processing and flexibility in tailoring the polymers' properties (37). Moreover, polyacrylates as saturated hydrocarbon polymers are highly resistant to oxidation; therefore stabilizers are not required to be added, as they may cause skin irritation (37).

Polyacrylates usually have a low value of the glass transition temperature $\left(T_{\mathrm{g}}\right)\left(-55\right.$ to $\left.-15^{\circ} \mathrm{C}\right)$ and are inherently tacky, such characteristics have two effects on application (37). One effect is that tackifiers and plasticizers generally are not required to be added to enhance the viscosity and softness of the polymers (37). The other effect is that polyacrylates are hard to mold into the desired shape owing to the low $T_{\mathrm{g}}$ value; thus polyacrylates are difficult to use as a rate-controlling membrane in TDDs. In our previous research, several film-form polyacrylates existing independently without support were synthesized and used successfully as the rate-controlling membrane in TDDs $(31,32)$. 
In the present work, a new polyacrylate membrane was synthesized and characterized by Fourier transform infrared spectroscopy (FTIR), differential scanning calorimetry (DSC), scanning electron microscopy (SEM), tensile strength, contact angles and swelling ratio. Five drugs were used as the models: 4-acetamidophenol, clonidine hydrochloride (clonidine $\mathrm{HCl}$ ), isosorbide dinitrate, scopolamine hydrobromide (scopolamine $\mathrm{HBr}$ ) and diltiazem hydrochloride (diltiazem $\mathrm{HCl}$ ). The effects on the drug permeability of the membranes' thickness, the acrylate monomers' ratios, the doses of the drugs and the drugs' physicochemical properties were studied and evaluated.

\section{Results and discussion}

\subsection{Synthesis and characterization of the acrylate copolymers with different formulations}

In previous works, polymers composed of 2-hydroxy-3-phenoxypropylacrylate (monomer A) and 4-hydroxybutyl acrylate (monomer B) (1:1 w/w) showed good mechanical and permeation properties $(38,39)$. Thus, the present work maintained such A/B optimal ratio but changed the content of the third monomer, cyclohexyl methacrylate (monomer C). The process of the synthesis of the polymers is shown in Figure 1.

When $3 \mathrm{mg} / \mathrm{ml}$ of clonidine $\mathrm{HCl}$ solution was transported through the membranes ( $14 \mu \mathrm{m}$ thickness) with different formulations, it was found that the permeation rate $(J)$ became higher with the general increase in monomer $\mathrm{C}$ content; however, there was no significant difference between M2 and M3 ( $p>0.05$ ) (Table 1). This result revealed that the structure and content of the monomers had important influences on the permeation. In a previous study (40), when the polymers were composed only of A and $\mathrm{B}$, the $J$ for the two drugs (methyl salicylate and naproxen) increased with increasing content of monomer B (Table 1S). Also, a molecular model utilizing the molecular mechanics 2 (MM2) energy minimization method included in the ChemBio3D Ultra 12.0 software (CambridgeSoft, MA, USA) optimized the geometry for the side groups on the $\mathrm{C}=\mathrm{C}$ double bond of the monomers (Figure 1S); it was found that the side groups of A were longer than those of B (Table 2S). Thus, a hypothesis was proposed stating that long side groups would occupy more inner space of the pores randomly fabricated by the polymer chains compared with the short side groups, resulting in the slow rate of drug transportation through the membrane. In this work, the side groups on the $\mathrm{C}=\mathrm{C}$ double bond of $\mathrm{C}$ were shorter than those of $\mathrm{A}$ and $\mathrm{B}$, and it was observed that the $J$ increased with increasing content of monomer $\mathrm{C}$, which verified the proposed hypothesis.

In contrast, it was known that the flexibility of the polymer chains decreased with increasing number of side groups on the $\mathrm{C}=\mathrm{C}$ double bond of the acrylate monomers. Thus, the membranes became more brittle and stiff as more monomer C was used in the formulations. This assumption was successfully verified by DSC. As shown by the DSC thermogram in Figure 2, the $T_{\mathrm{g}}$ value of seven formulations - M1, M2, M3, M4, M5, M6 and M7 was $16.3^{\circ} \mathrm{C}, 19.9^{\circ} \mathrm{C}, 31.6^{\circ} \mathrm{C}, 38.4^{\circ} \mathrm{C}, 42.7^{\circ} \mathrm{C}, 55.1^{\circ} \mathrm{C}, 63.0^{\circ} \mathrm{C}$, respectively. These $T_{\mathrm{g}}$ values became higher with increasing monomer $\mathrm{C}$. This provided an explanation as to why the membranes became stiff with increasing monomer $\mathrm{C}$ content. Moreover, these $T_{\mathrm{g}}$ values were much higher than those of traditional polyacrylate pressure-sensitive adhesives, which allowed our polymers to show a flexible or stiff film appearance at room temperature.

Figure 3 shows the mechanical properties of the films with different formulations. As shown in the figure, the changes in the flexibility or ductility of the films depend

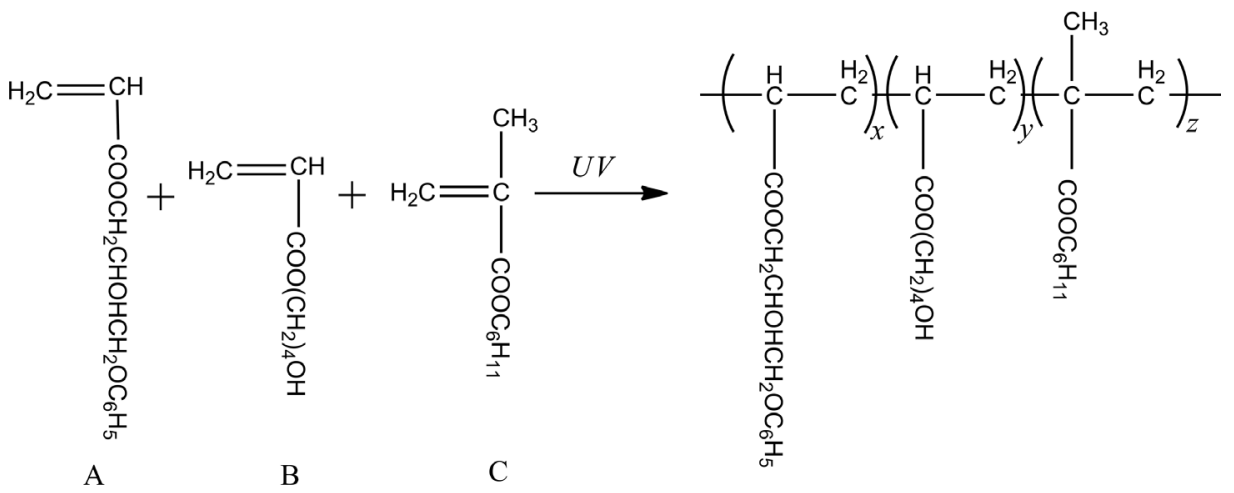

Figure 1 The process of synthesis of polyacrylates. 
Table 1 Effects of the ratio of the monomers on the permeation of clonidine $\mathrm{HCl}$.

\begin{tabular}{|c|c|c|c|}
\hline Formulation & $\mathrm{A} / \mathrm{B} / \mathrm{C}$ & $J\left[\mu \mathrm{g} /\left(\mathrm{cm}^{2} \mathrm{~h}\right)\right]$ & $\begin{array}{r}\text { Correlation } \\
\text { coefficient }(r)\end{array}$ \\
\hline$M 1^{a}$ & $4.5: 4.5: 1$ & $26.5 \pm 0.2$ & 0.9935 \\
\hline$M 2^{\mathrm{a}}$ & $4: 4: 2$ & $31.9 \pm 0.3$ & 0.9986 \\
\hline $\mathrm{M}^{\mathrm{a}}$ & $3.5: 3.5: 3$ & $32.2 \pm 0.9$ & 0.9993 \\
\hline$M 4^{\mathrm{a}}$ & $3: 3: 4$ & $41.4 \pm 0.6$ & 0.9779 \\
\hline$M 5^{\mathrm{a}}$ & $2.5: 2.5: 5$ & $50.4 \pm 0.9$ & 0.9974 \\
\hline$M 6^{\mathrm{a}}$ & $2: 2: 6$ & $N D^{b}$ & $N D^{b}$ \\
\hline$M 7^{a}$ & $1: 1: 8$ & $N D^{b}$ & $N D^{\mathrm{h}}$ \\
\hline
\end{tabular}

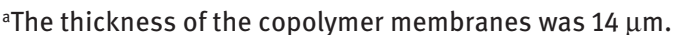
${ }^{\mathrm{b}} \mathrm{ND}$, not determined because of the poor flexibility of the membranes.

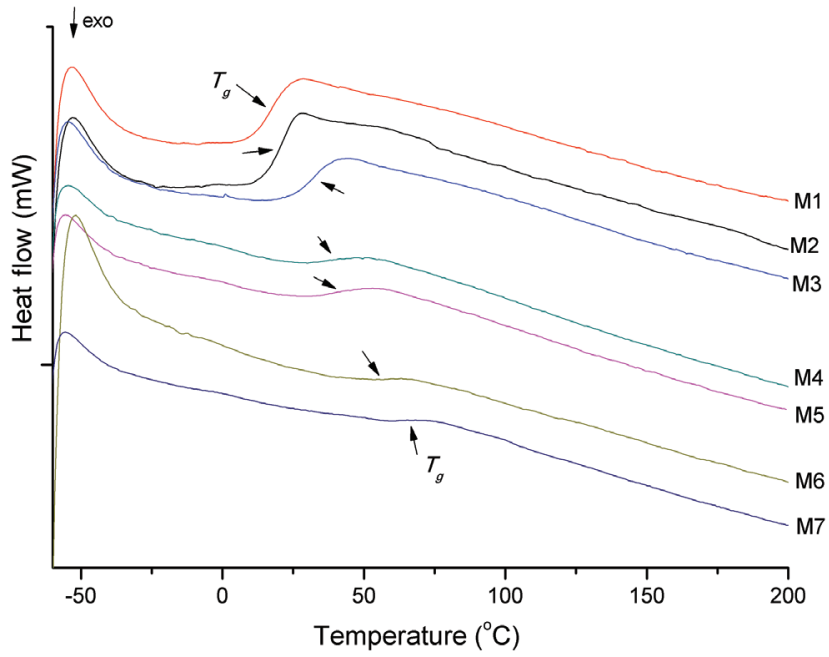

Figure 2 DSC thermograms of the polyacrylates with different formulations.

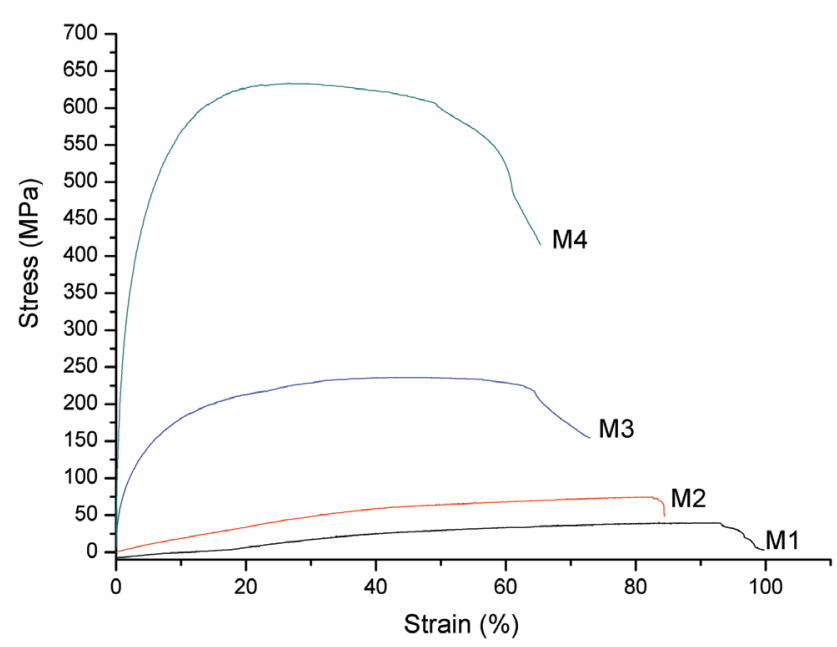

Figure 3 Stress-strain curve of the polyacrylates with different formulations. on the content of monomer C. The ductility of the films decreased with increasing monomer $\mathrm{C}$ content, which could be due to the restricted mobility of the polymer chains caused by the increased stiffness of the film. The films became very brittle when the amount of monomer C was increased to $50 \%$, which resulted in films that were easily broken at the pressed areas.

The FTIR spectra of seven formulations were similar (Figure 4); here the datum of M2 is shown in detail: the wide peak of $3427 \mathrm{~cm}^{-1}$ was the stretching vibration of O-H; 2933 and $2858 \mathrm{~cm}^{-1}$ were the stretching vibrations of C-H; 1594, 1490, 1445 and $1389 \mathrm{~cm}^{-1}$ were the aromatic ring skeleton vibrations; 748 and $688 \mathrm{~cm}^{-1}$ were the bending vibration of $\mathrm{C}-\mathrm{H}$ in the aromatic ring; $1716 \mathrm{~cm}^{-1}$ was the stretching vibration of $\mathrm{C}=0$ in the ester group; $1162 \mathrm{~cm}^{-1}$ was the stretching vibration of $\mathrm{C}-\mathrm{O}-\mathrm{C}$ in the ester group; $1231 \mathrm{~cm}^{-1}$ was the stretching vibration of $\mathrm{C}-\mathrm{O}$ in $\mathrm{O}-\mathrm{C}_{6} \mathrm{H}_{5}$; $1114 \mathrm{~cm}^{-1}$ was the stretching vibration of $\mathrm{C}-\mathrm{O}$ in $\mathrm{CHOH}$; and $1034 \mathrm{~cm}^{-1}$ was the stretching vibration of $\mathrm{C}-\mathrm{O}$ in $\mathrm{CH}_{2} \mathrm{OH}$.

After considering both the permeation and the flexibility of the membranes, the M2 formulated A, B and C monomers at a ratio of 4:4:2(w/w/w) were chosen as the optimal membranes and were used to evaluate the permeation of different drugs.

\subsection{Characterization of the $M 2$}

In SEM determination, the M2 showed a smooth surface (Figure 5).

The M2 exhibited an 8\% swelling ratio, which shows that the membrane swelled slightly owing to the hydroxyl

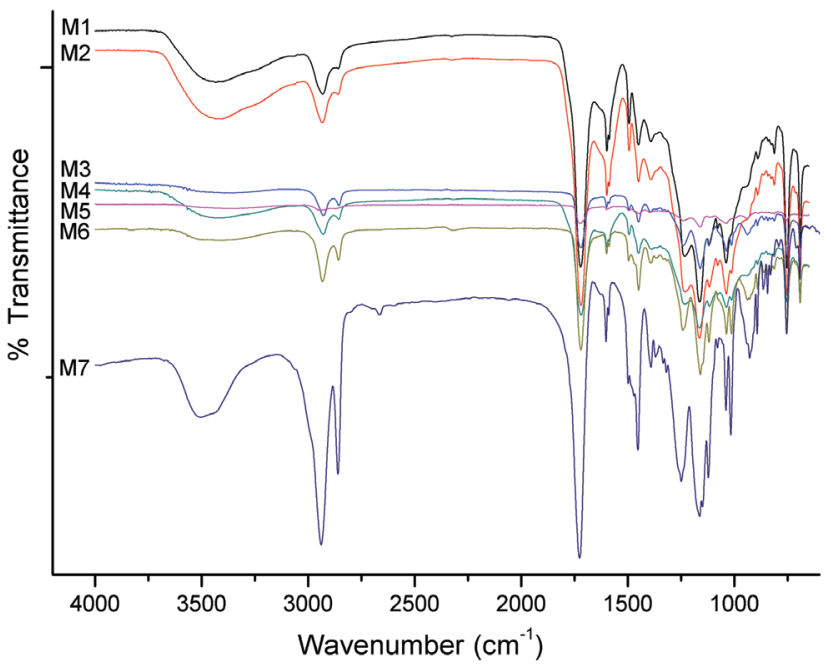

Figure 4 FTIR spectra of the polyacrylates with different formulations. 


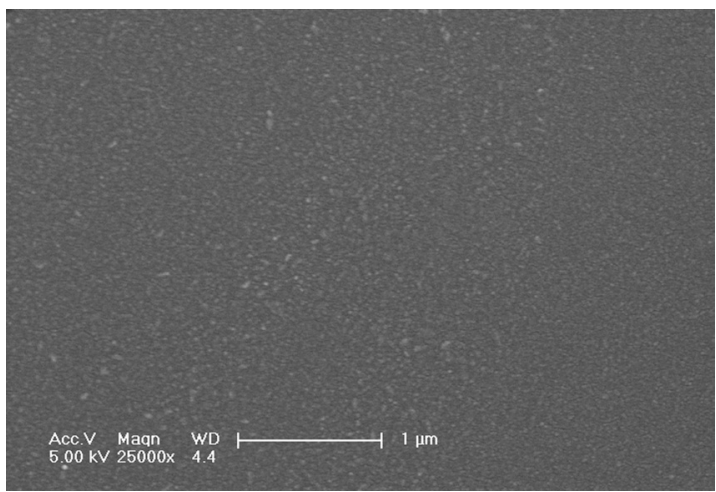

Figure 5 Scanning electron micrograph of the M2 (original magnification $\times 25,000$ ).

groups on the side chains. The M2 could not be eroded either, with a $0 \%$ erosion ratio.

The contact angle of the M2 was $70.7^{\circ}$ (Figure 6), which indicates that the surface of the M2 was slightly wetted by water; this result was consistent with the low swelling ratio of the M2.

\subsection{Effect of the membrane's thickness on the permeation}

Different thicknesses - 14, 30 and $44 \mu \mathrm{m}$, respectively - of the M2 were used as the rate-controlling membrane, and the permeation properties of $3 \mathrm{mg} / \mathrm{ml}$ of clonidine $\mathrm{HCl}$ solution transporting through the M2 were studied. Table 2 shows that an increase in the thickness of the M2 resulted in a decrease in the amount of clonidine $\mathrm{HCl}$ transporting through the membrane. This result could be explained by Fick's law, as given by Equation [1]:

$$
J=\frac{1}{A} \frac{\mathrm{d} M_{t}}{\mathrm{dt}}=P \frac{\Delta C}{L}
$$

where $J$ is the permeation rate, $\mathrm{d} M_{\mathrm{t}} / \mathrm{d} t$ is the mass of the solute that permeates through the membrane in a unit

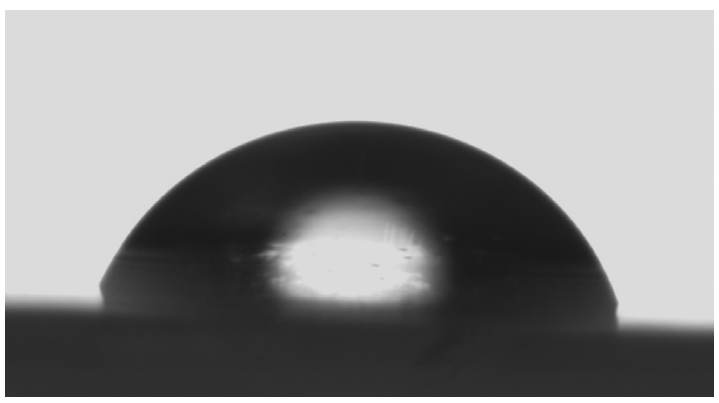

Figure 6 Contact angle photograph of the M2.
Table 2 Effects of the thickness of the membrane on the permeation of clonidine $\mathrm{HCl}$.

\begin{tabular}{lrr}
\hline $\begin{array}{l}\text { Thickness } \\
(\mu \mathrm{m})\end{array}$ & $J\left[\mu \mathrm{g} /\left(\mathrm{cm}^{2} \mathrm{~h}\right)\right]$ & $\begin{array}{r}\text { Correlation } \\
\text { coefficient }(r)\end{array}$ \\
\hline 14 & $31.9 \pm 0.3$ & 0.9986 \\
30 & $12.3 \pm 0.3$ & 0.9781 \\
44 & $7.3 \pm 0.01$ & 0.9785 \\
\hline
\end{tabular}

time, $A$ is the permeation area, $\Delta C$ is the concentration difference between the donor cell and the receptor cell, $P$ is the permeability coefficient and $L$ is the thickness of the rate-controlling membrane (41).

From Equation [1], it was determined that the thickness of the membrane was an important factor influencing the permeation of the drug molecules. When $J$ and $1 / L$ were fitted by a linear equation, it was found that a perfect linear relationship was exhibited, with a correlation coefficient $(r)$ value of 0.9995 (figure not shown). Similar results were obtained from a rubber film (34).

\subsection{Effect of the drugs' physicochemical properties on the permeation}

Higo (42) claimed that the $J$ of the drugs could be influenced by many factors including the molecular weight $\left(M_{\mathrm{w}}\right)$, octanol/water partition rate $\left(\log K_{\mathrm{o} / \mathrm{w}}\right)$ and melting point (MP) of the drugs. Table 3 lists the $J$ of the five drugs (3 $\mathrm{mg} / \mathrm{ml}$ donor concentration) transported through the M2 (14 $\mu \mathrm{m}$ thickness) and their physicochemical parameters. It was found that it was difficult to show a simple relationship between the $J$ and the physicochemical parameters of the drugs. Five drugs were divided into two groups: the first group included clonidine, scopolamine and diltiazem, which were processed into salts and dissolved in water as the donor solution. The second group consisted of 4-acetamidophenol and isosorbide dinitrate, which hardly dissolved in water and, thus, 10\% (v/v) 1,2-propanediol in water was used as the donor medium

Table 3 The $/$ and the physicochemical parameters of the drugs.

\begin{tabular}{lrrrr}
\hline Drug $^{\mathrm{a}}$ & $\boldsymbol{J}\left[\boldsymbol{\mu g} /\left(\mathrm{cm}^{2} \mathbf{h}\right)\right]$ & $\boldsymbol{M}_{\mathrm{w}}$ & $\log \boldsymbol{K}_{\mathrm{o} / \mathrm{w}}$ & $\boldsymbol{M P}\left({ }^{\circ} \mathrm{C}\right)$ \\
\hline 4-Acetamidophenol & 26.017 & 151.16 & $0.31(43)$ & 170 \\
Clonidine & 31.705 & 230.09 & $0.83(42)$ & 140 \\
Isosorbide dinitrate & 77.011 & 236.14 & $1.31(44)$ & 69 \\
Scopolamine & 19.004 & 303.35 & $1.24(42)$ & 59 \\
Diltiazem & 4.071 & 414.52 & $2.70(45)$ & 212 \\
\hline
\end{tabular}

aThe concentration of all drugs in the donor cell was $3 \mathrm{mg} / \mathrm{ml}$. 

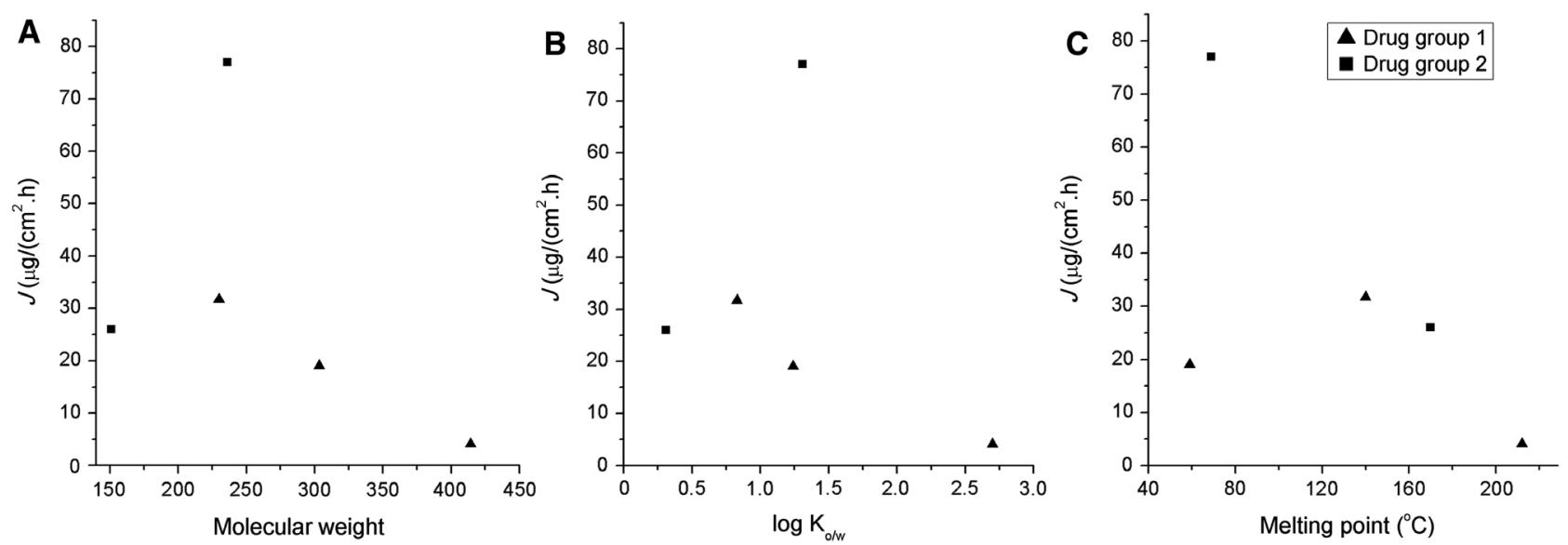

Figure 7 The relationship between $J$ and (A) $M_{w}$, (B) $\log K_{o / w}$ and (C) MP.

instead. In the first group, the $J$ became larger with lower $M_{\mathrm{w}}$ and lower $\log K_{\mathrm{o} / \mathrm{w}}$. But the results of the second group were the opposite of those of the first group. At the MP, the $J$ became larger as the MP of the drugs became lower except for scopolamine (Figure 7). According to the claims proposed by Higo (42), the $J$ of drugs became larger with lower MP, lower $M_{\mathrm{w}}$ and moderate $\log K_{\mathrm{o} / \mathrm{w}^{*}}$ The results of the first group conformed to his claims better than those of the second group.

In general, the $J$ decreased with the increase in the size of the drug molecule, which simplifies to $J$ decreasing with increasing $M_{\mathrm{w}}$ of the drug. However, 4-acetamidophenol and isosorbide dinitrate showed an anomalistic pattern. The reason is that 4-acetamidophenol (illustrated in Figure 8) with two H-donors and three $\mathrm{H}$-acceptors generated intermolecular H-bonds and further led to the sharp increase in molecular size, but the $M_{\mathrm{w}}$ of isosorbide dinitrate without $\mathrm{H}$-donors did not readily increase.
The lipophilicity of the drug also had an influence on the permeation. It was found that the $\log K_{\mathrm{o} / \mathrm{w}}$ of clonidine, scopolamine and diltiazem was $0.83,1.24$ and 2.7, respectively. Their corresponding $J$ was 31.705, 19.004 and 4.071, respectively. According to the rule of "likes dissolve likes", the hydrophilicity of a drug promoted the transportation of the drug through the membrane because the surface of the M2 was slightly hydrophilic. Conversely, the $\log K_{\mathrm{o} / \mathrm{w}}$ of 4-acetamidophenol and isosorbide dinitrate was 0.31 and 1.31, respectively, and their corresponding $J$ was 26.017 and 77.011, respectively. This indicates that other effects accelerated the drug permeation. With 1,2-propanediol as the donor medium, their $\log K_{\mathrm{o} / \mathrm{w}}$ was -0.92 (recorded in International Programme on Chemical Safety, ICSC:0321); thus it would obviously promote permeation. However, the molecular size of 4-acetamidophenol became large by self-aggregation, which resulted in the decrease in the permeation.

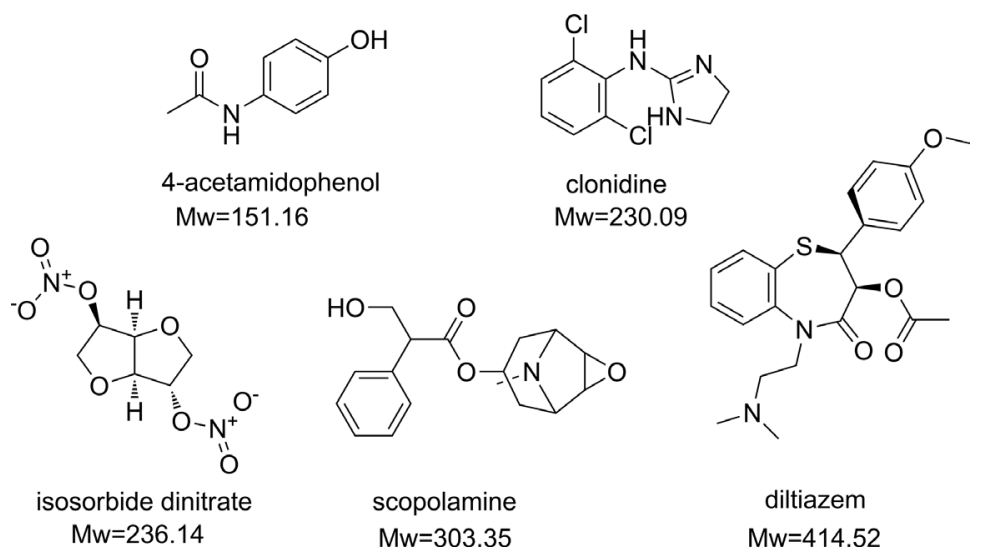

Figure 8 Illustration of the structure and molecular weight of the drug molecules. 


\subsection{Effects of the drug dose on the permeation}

In order to evaluate the effects of the doses of different drugs on the permeation, clonidine and isosorbide dinitrate were used as the model drugs because their molecular weights were similar, but their $J$ values were significantly different in the same administration concentration of $3 \mathrm{mg} / \mathrm{ml}$ (Table 3). The $J$ for clonidine $\mathrm{HCl}$ solution $(0.5,1.0,3.0,5.0$ and $7.0 \mathrm{mg} / \mathrm{ml})$ transporting through the 14- $\mu \mathrm{m}$-thick M2 was compared with that of isosorbide dinitrate solution (1.0, 2.0, 3.0 and $5.0 \mathrm{mg} / \mathrm{ml}$ ) (Figure 9). We could observe a platform for $J$ when the amount of clonidine $\mathrm{HCl}$ was varied from 3.0 to $5.0 \mathrm{mg} / \mathrm{ml}(\mathrm{p}>0.05)$, which was similar to known polyacrylate membranes in the literatures $(38,39)$. However, for isosorbide dinitrate, the $J$ could be fitted with the concentration by a linear equation, with a correlation coefficient $(r)$ of up to 0.9997 (figure not shown).

The reason why the same membrane presented a different permeation behavior to different drugs was possibly that there was an intermolecular interaction between drug molecules and polymer chains. As the polyacrylate was a non-degradable and water-insoluble polymer, the rate of drug transport through the polyacrylate was limited by the rate of the drug diffusion rather than by the polymer's dissolution and degradation (46). Due to numerous hydroxyl groups and ester groups on the polyacrylate chains, intermolecular $\mathrm{H}$-bonds were generated during the process of diffusion of clonidine $\mathrm{HCl}$ and, subsequently, some clonidine molecules were captured by the polymer chains. The actual number of free clonidine molecules did not increase yet when the dose of clonidine

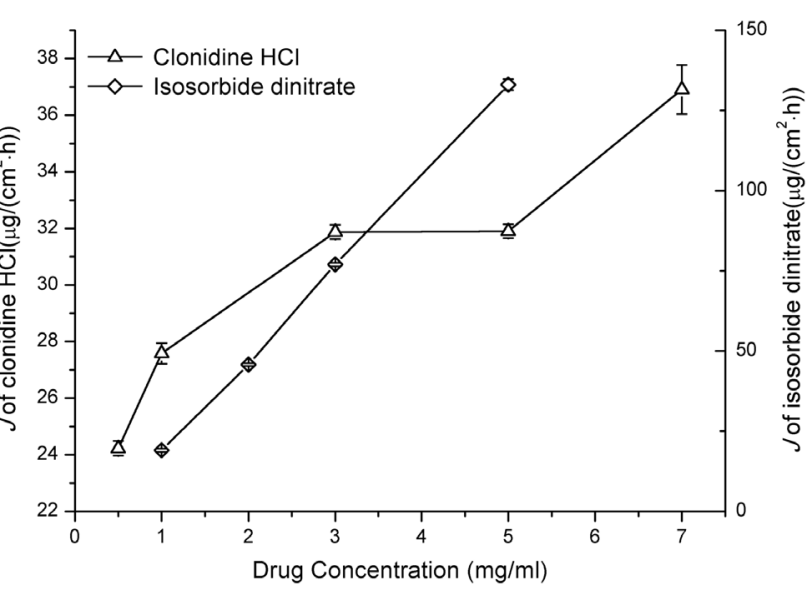

Figure 9 Graph of the / and drug concentration of clonidine $\mathrm{HCl}$ and isosorbide dinitrate being transported through the M2. was increased from 3 to $5 \mathrm{mg}$, which resulted in a platform for the $J$. With the continuous increase in the drug dose, the captured clonidine molecules became saturated and the $J$ increased with a further increase in the dose of clonidine (39).

However, as isosorbide dinitrate had no H-donors, it was difficult to generate intermolecular H-bonds, which resulted in a dose-dependent permeation behavior. Thus, because the M2 presented different permeation behavior to different drugs, it was used as a rate-controlling membrane in the TDDs to achieve the expected requirement.

\section{Conclusions}

In this study, a new type of acrylate copolymer with different formulations was prepared via a UV curing method, using 2-hydroxy-3-phenoxypropylacrylate, 4-hydroxybutyl acrylate and cyclohexyl methacrylate monomers. The M2 showed perfect mechanical and permeation properties, and the $J$ of the M2 showed a thickness-dependent relationship. Furthermore, the M2 exhibited different permeation behaviors during the process of transport of different drugs through the M2. The results indicated that the permeation behavior was complicated, as many factors influenced the permeation including the molecular size, $\log K_{\mathrm{o} / \mathrm{w}}$ and dose of the drug, and the interaction between the drugs and the membrane material. This new acrylate copolymer material might open new applications in the field of TDDs.

\section{Experimental part}

\subsection{Materials}

2-Hydroxy-3-phenoxypropylacrylate, 4-hydroxybutyl acrylate and cyclohexyl methacrylate (Sigma-Aldrich Corporation, Madison, WI, USA) were purified by vacuum distillation under reduced pressure and stored at $4^{\circ} \mathrm{C}$ for further use. Benzoyl peroxide, 4-acetamidophenol and clonidine $\mathrm{HCl}$ (National Medicine Corporation, Shanghai, China) were used as received. Isosorbide dinitrate (Shanghai Yuanji Chemical Co. Ltd., Shanghai, China) and scopolamine $\mathrm{HBr}$ (Merck, Shanghai, China) were used as received. Diltiazem $\mathrm{HCl}$ was obtained as a gift sample from Shanghai Pharma Corporation (Shanghai, China). All the other chemicals received were of the highest purity and used without further purification. 


\subsection{Synthesis of film-like acrylate copolymer}

Three UV-curable acrylate monomers with different ratios (Table 1) mixed with photo-initiators (3\% benzoyl peroxide) were dissolved completely and then placed on a quartz substrate (diameter of $30 \mathrm{~mm}$ ). The quartz substrate was treated under UV light (UV spectrum: 200-400 nm; power: $3 \mathrm{~kW}$ ); the distance from the quartz substrate to the UV lamp was $12 \mathrm{~cm}$, and the mixture was polymerized by UV light for $\sim 5 \mathrm{~min}$. Finally, the cured polyacrylate membranes were carefully separated from the quartz substrate. After the demolding, the membranes were further washed with distilled water repeatedly to eliminate the residues of the monomers and initiators, and then stored in distilled water. The reactive equation of the polymerization is shown in Figure 1.

\subsection{Characterization of the copolymer membrane}

FTIR was performed on a Nicolet iS10 FT-IR spectrometer (ThermoScientific, Waltham, MA, USA). The thin freezedry film was scanned directly by an attenuated total reflection accessory equipped with a ZnSe crystal at a resolution of $4 \mathrm{~cm}^{-1}$ with 16 times of scanning over a wavenumber range of $600-4000 \mathrm{~cm}^{-1}$.

The $T_{g}$ of the films was determined by DSC (DSC 204F1, Netzsch, Selb, Germany). The film samples weighing approximately $5 \mathrm{mg}$ were first heated from $20^{\circ} \mathrm{C}$ to $200^{\circ} \mathrm{C}$ at a heating rate of $10^{\circ} \mathrm{C} / \mathrm{min}$ and then held for $5 \mathrm{~min}$ to eliminate the thermal history. Subsequently, the samples were cooled to $-60^{\circ} \mathrm{C}$ under a $\mathrm{N}_{2}$ atmosphere and then heated again from $-60^{\circ} \mathrm{C}$ to $200^{\circ} \mathrm{C}$ at a rate of $10^{\circ} \mathrm{C} / \mathrm{min}$.

Tensile strength was tested using the AI-3000 tester (Gotech, Guangzhou, China). The film was cut into a shape with a length of $10 \mathrm{~mm}$, width of $5 \mathrm{~mm}$ and thickness of $0.5 \mathrm{~mm}$. The tensile speed was set at $1 \mathrm{~mm} / \mathrm{min}$, and the initial grip separation was $5 \mathrm{~mm}$. The stress-strain tensile curve of the films was recorded.

SEM analysis was performed by using a Sirion 200 scanning electron microscope (FEI, Eindhoven, The Netherlands). Before the SEM analysis, the film was freeze-dried in a vacuum and then sputtered with gold coating.

The static contact angles for the film were determined by the sessile drop method at room temperature and a controlled humidity. One-microliter drop of deionized water was placed on the film surface; the contact angles were recorded in $30 \mathrm{~s}$ using a contact angle system (OCA 20,
Dataphysics Instruments $\mathrm{GmbH}$, Filderstadt, Germany) at five different locations on the surface. Then, the average value was calculated.

The swelling and erosion ratios of the films were determined. Each freeze-dry membrane was weighed and recorded $\left(W_{0}\right)$. Then the film was immersed in distilled water at room temperature for $48 \mathrm{~h}$. The hydrated film was blotted with filter paper to remove excess water, and the new weight $\left(W_{\mathrm{s}}\right)$ was recorded. Then, the film was dried in an oven at $60 \pm 2^{\circ} \mathrm{C}$ overnight, reweighed and the new weight $\left(W_{\mathrm{d}}\right)$ recorded. The swelling ratio and the erosion ratio were calculated following Equations [2] and [3] (47).

$$
\begin{aligned}
& \text { Swelling ratio(\%) }=\frac{W_{\mathrm{s}}-W_{0}}{W_{0}} \times 100 \\
& \text { Erosion ratio }(\%)=\frac{W_{0}-W_{\mathrm{d}}}{W_{0}} \times 100
\end{aligned}
$$

\subsection{Drug permeation experiments}

The tested film was blotted with filter paper to remove excess water and then mounted on a modified Franz diffusion cell with $0.785 \mathrm{~cm}^{2}$ of effective diffusion area. There was a 1-ml drug solution in the donor compartment, where clonidine $\mathrm{HCl}$, scopolamine $\mathrm{HBr}$ and diltiazem $\mathrm{HCl}$ were dissolved in water as the donor solution; 4-acetamidophenol and isosorbide dinitrate were dissolved in $10 \%(\mathrm{v} / \mathrm{v})$ 1,2-propanediol/water as the donor solution. The receptor compartment was filled with a phosphate buffer solution $(0.01 \mathrm{~mol} / \mathrm{l}, \mathrm{pH}$ 7.4) for clonidine $\mathrm{HCl}$, scopolamine $\mathrm{HBr}$ and diltiazem $\mathrm{HCl}$, or with $10 \%$ (v/v) 1,2-propanediol/water for 4-acetamidophenol and isosorbide dinitrate, and then maintained in a water bath at $37 \pm 0.5^{\circ} \mathrm{C}$. The receptor medium was stirred constantly at $200 \mathrm{rpm}$. At predetermined time intervals, the receptor solution was withdrawn and then replaced with an equal volume of fresh receptor medium. The samples were analyzed at a specific maximum absorption wavelength $\left(\lambda_{\max }\right)$ using a UV-Vis spectrophotometer (DU800, Beckman, Fullerton, CA, USA): 4-acetamidophenol, $\lambda_{\text {max }}=243 \mathrm{~nm}$; clonidine $\mathrm{HCl}, \lambda_{\text {max }}=220 \mathrm{~nm}$; isosorbide dinitrate, $\lambda_{\max }=220 \mathrm{~nm}$; scopolamine $\mathrm{HBr}, \lambda_{\max }=210 \mathrm{~nm}$; and diltiazem $\mathrm{HCl}, \lambda_{\max }=240 \mathrm{~nm}$.

\subsection{Data analysis}

The cumulative amount of drug being transported through the rate-controlling membrane was calculated following Equation [4]: 


$$
Q=\frac{C_{n} V+\sum_{i=1}^{i=n-1} C_{i} V_{i}}{A}
$$

where $Q$ is the cumulative amount of drug permeation $\left(\mu \mathrm{g} / \mathrm{cm}^{2}\right) ; V$ is the receptor solution volume $(\mathrm{ml}) ; V_{i}$ is the sample volume (ml); $C_{n}$ and $C_{i}$ are the drug concentration $(\mu \mathrm{g} / \mathrm{ml})$ of the receptor cell and the extracted sample, respectively; and $A$ is the transporting area $\left(\mathrm{cm}^{2}\right)$.

When the cumulative drug amount $\left(Q_{t}, \mu \mathrm{g} / \mathrm{cm}^{2}\right)$ was plotted vs. time $(T, h)$, the slope of the linear portion of the plot was presented as the permeation rate $\left(J, \mu \mathrm{g} / \mathrm{cm}^{2}\right.$ per hour). The intercept on the $x$-axis was presented as the lag time $\left(T_{\mathrm{L}}, \mathrm{h}\right)$. All of the permeation experiments were repeated three times from an independent batch, and the mean values of the permeation rates with standard deviations were calculated. One-way analysis of variance was used to determine the statistically significant differences. The $\mathrm{p}$ value used in this study was 0.05 .

Acknowledgments: This work was supported by the National Significant and Special Project of New Created Drugs (no. 2010ZX09401-404).

\section{References}

1. Prausnitz MR, Langer R. Transdermal drug delivery. Nat Biotechnol. 2008;26(11):1261-8.

2. Stamatialis DF, Papenburg BJ, Gironés M, Saiful S, Bettahalli SNM, Schmitmeier S, Wessling M. Medical applications of membranes: drug delivery, artificial organs and tissue engineering. J Membr Sci. 2008;308(1-2):1-34.

3. Tan HS, Pfister WR. Pressure-sensitive adhesives for transdermal drug delivery systems. Pharm Sci Technol Today 1999;2(2):60-9.

4. Subedi RK, Oh SY, Chun MK, Choi HK. Recent advances in transdermal drug delivery. Arch Pharm Res. 2010;33(3):339-51.

5. Chen CH, Hsieh MF, Ho YN, Huang CM, Lee JS, Yang CY, Chang Y. Enhancement of catechin skin permeation via a newly fabricated mPEG-PCL-graft-2-hydroxycellulose membrane. J Membr Sci. 2011;371(1-2):134-40.

6. Tirnaksiz F, Yuce Z. Development of transdermal system containing nicotine by using sustained release dosage design. II Farmaco 2005;60(9):763-70.

7. Garg T, Singh S, Goyal AK. Stimuli-sensitive hydrogels: an excellent carrier for drug and cell delivery. Crit Rev Ther Drug Carr Syst. 2013;30(5):369-409.

8. Siegel RA, Gu Y, Lei M, Baldi A, Nuxoll EE, Ziaie B. Hard and soft micro- and nanofabrication: an integrated approach to hydrogel-based biosensing and drug delivery. J Control Rel. 2010;141(3):303-13.

9. Pal K, Banthia AK, Majumdar DK. Polymeric hydrogels: characterization and biomedical applications. Des Monomers Polym. 2009;12(3):197-220.
10. Oh JK, Drumright R, Siegwart DJ, Matyjaszewski K. The development of microgels/nanogels for drug delivery applications. Prog Polym Sci. 2008;33(4):448-77.

11. Kulkarni RV, Biswanath SA. Electrically responsive smart hydrogels in drug delivery: a review. J Appl Biomater Biom. 2007;5(3):125-39.

12. Xu Q, Huang W, Jiang L, Lei Z, Li X, Deng H. KGM and PMAA based $\mathrm{pH}$-sensitive interpenetrating polymer network hydrogel for controlled drug release. Carbohyd Polym. 2013;97(2):565-70.

13. Denkbas EB, Ottenbrite RM. Perspectives on: chitosan drug delivery systems based on their geometries. J Bioact Compat Pol. 2006;21(4):351-68.

14. Vaghani SS, Patel MM, Satish CS, Patel KM, Jivani NP. Synthesis and characterization of carboxymethyl chitosan hydrogel: application as ph-sensitive delivery for nateglinide. Curr Drug Delivery 2012;9(6):628-36.

15. Wang W, Zhang P, Shan W, Gao J, Liang W. A novel chitosanbased thermosensitive hydrogel containing doxorubicin liposomes for topical cancer therapy. J Biomat Sci Polym E 2013;24(14):1649-59.

16. Ngoc-Thang N, Liu J. Fabrication and characterization of poly(vinyl alcohol)/chitosan hydrogel thin films via UV irradiation. Eur Polym J. 2013;49(12):4201-11.

17. Pawar SN, Edgar KJ. Alginate derivatization: a review of chemistry, properties and applications. Biomaterials 2012;33(11):3279-305.

18. Oh JK, Lee DI, Park JM. Biopolymer-based microgels/nanogels for drug delivery applications. Prog Polym Sci. 2009;34(12):1261-82.

19. Liang D, Hsiao BS, Chu B. Functional electrospun nanofibrous scaffolds for biomedical applications. Adv Drug deliver Rev. 2007;59(14):1392-412.

20. Chen DW, Hsu Y, Liao J, Liu S, Chen J, Ueng SW. Sustainable release of vancomycin, gentamicin and lidocaine from novel electrospun sandwich-structured PLGA/collagen nanofibrous membranes. Int J Pharm. 2012;430(1-2):335-41.

21. Parizek M, Douglas TE, Novotna K, Kromka A, Brady MA, Renzing A, Voss E, Jarosova M, Palatinus L, Tesarek P, Ryparova P, Lisa V, Santos AM. Bacakova L. Nanofibrous poly(lactide-co-glycolide) membranes loaded with diamond nanoparticles as promising substrates for bone tissue engineering. Int J Nanomed. 2012;7:1931-51.

22. Han D, Steckl AJ. Triaxial electrospun nanofiber membranes for controlled dual release of functional molecules. Appl Mater Interfaces 2013;5(16):8241-5.

23. Kudaibergenov SE, Nuraje N, Khutoryanskiy VV. Amphoteric nano-, micro-, and macrogels, membranes, and thin films. Soft Matter 2012;8(36):9302-21.

24. Ladika M, Kalantar TH, Shao H, Dean SL, Harris JK, Sheskey PJ, Coppens K, Balwinski KM, Holbrook DL. Polyampholyte acrylic latexes for tablet coating applications. J Appl Polym Sci. 2014;131(7). Available at: http://onlinelibrary.wiley.com/ doi/10.1002/app.40049/abstract (accessed Dec 24, 2014).

25. Ng L, Ng K. Photo-cured pH-responsive polyampholytecoated membranes for controlled release of drugs with different molecular weights and charges. Radiat Phys Chem. 2008;77(2):192-9.

26. Fang JY, Huang YB, Wang HY, Tsai YH. Electrically-assisted skin permeation of two synthetic capsaicin derivatives, sodium nonivamide acetate and sodium nonivamide propionate, via 
rate-controlling polyethylene membranes. Biol Pharm Bull. 2005;28(9):1695-701.

27. Tang M, Hou J, Lei L, Liu X, Guo S, Wang Z, Chen K. Preparation, characterization and properties of partially hydrolyzed ethylene vinyl acetate copolymer films for controlled drug release. Int J Pharm. 2010;400(1-2):66-73.

28. Kim MK, Zhao H, Lee CH, Kim DD. Formulation of a reservoirtype testosterone transdermal delivery system. Int J Pharm. 2001;219(1-2):51-9.

29. Babu RJ, Pandit JK. Effect of penetration enhancers on the release and skin permeation of bupranolol from reservoir-type transdermal delivery systems. Int J Pharm. 2005;288(2):325-34.

30. El-Newehy MH, Al-Deyab SS, Kenawy ER, Abdel-Megeed A. Nanospider technology for the production of nylon- 6 nanofibers for biomedical applications. J Nanomater. 2011; article ID 626589.

31. Zhan X, Chen S, Tang G, Mao Z. A new poly(2-hydroxy-3-phenoxypropylacrylate, 4-hydroxybutyl acrylate, diethyl maleate) membrane controlled clonidine linear release in the transdermal drug delivery system. Eur Polym J. 2007;43(4):1588-94.

32. Zhan X, Chen S, Tang G, Mao Z. Poly(2-hydroxy-3-phenoxypropylacrylate, 4-hydroxybutyl acrylate, dibutyl maleate) membrane controlled clonidine zero-order release. Eur J Pharm Biopharm. 2007;66(3):429-34.

33. Suksaeree J, Pichayakorn W, Monton C, Sakunpak A, Chusut T, Saingam W. Rubber polymers for transdermal drug delivery systems. Ind Eng Chem Res. 2014;53(2):507-13.

34. Pichayakorn W, Suksaeree J, Boonme P, Taweepreda W, Amnuaikit T, Ritthidej GC. Deproteinised natural rubber used as a controlling layer membrane in reservoir-type nicotine transdermal patches. Chem Eng Res Des. 2013;91(3):520-9.

35. Gargiulo N, Santo ID, Causa F, Caputo D, Netti PA. Confined mesoporous silica membranes for albumin zero-order release. Micropor Mesopor Mat. 2013;167:71-5.

36. Su Y, Qiao S, Yang H, Yang C, Jin Y, Stahr F, Sheng J, Cheng L, Ling C, Lu GQ. Titanate-silica mesostructured nanocables: synthesis, structural analysis and biomedical applications. Nanotechnology 2010;21(6): article ID 065604.
37. Sun F, Zhu G, Li S, Du H. Synthesis and characterization of a solvent-based acrylate pressure adhesive for transdermal drug delivery. e-Polymers 2009;129:1-12.

38. Zhan X, Chen S, Tang G, Mao Z. Two new types of copolymer membranes controlling clonidine zero-order. Release J Appl Polym Sci. 2007;106(5):3016-22.

39. Zhan X, Tang G, Chen S, Mao Z. A new copolymer membrane controlling clonidine linear release in a transdermal drug delivery system. Int J Pharm. 2006;322(1-2):1-5.

40. Mao Z, Zhan X. An acrylate composition having an ester moiety with a hydroxyl group. 2005; CN1687160.

41. Zhan X, Chen S, Tang G, Mao Z. A new copolymer membrane cured by 2-hydroxy-3-phenoxypropylacrylate, 4-hydroxybutyl acrylate, and isobutyl methacrylate controlled clonidine linear release in the transdermal drug delivery system. Polym Adv Technol. 2007;18(5):392-6.

42. Higo N. The recent trend of transdermal drug delivery system development. Yakugaku Zasshi -J Pharm Soc J. 2007;127(4):655-62.

43. IARC. IARC monographs on the evaluation of carcinogenic risks to humans. Pharmaceut Drugs, Lyon 1990;50:307-32.

44. CAS No. 87-33-2. http://www.guidechem.com/reference/dic940.html (accessed 17 December 2014).

45. Hansch C, Leo A, Hoekman D. Exploring QSAR. Hydrophobic, electronic, and steric constants. ACS Professional Reference Book. Washington, DC: American Chemical Society; 1995.

46. Kılıçay E, Çakmaklı B, Hazer B, Denkbaş EB, Açıkgöz B. Acetylsalicylic acid loading and release studies of the PMMA-g-polymeric oils/oily acids micro and nanospheres. J Appl Polym Sci. 2011;119(3):1610-8.

47. Pichayakorn W, Suksaeree J, Boonme P, Amnuaikit T, Taweepreda W, Ritthidej GC. Deproteinized natural rubber latex/ hydroxypropylmethyl cellulose blending polymers for nicotine matrix films. Ind Eng Chem Res. 2012;51(5):8442-52.

Supplemental Material: The online version of this article (DOI: 10.1515/epoly-2014-0123) offers supplementary material, available to authorized users. 